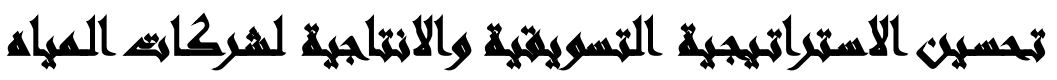

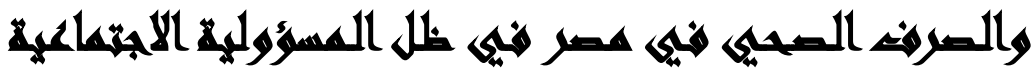

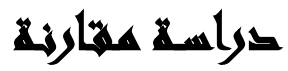

[ir]

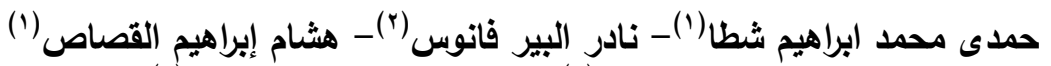

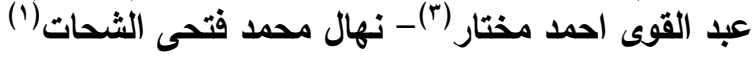

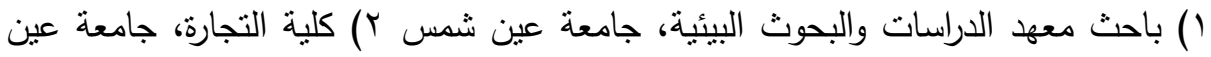
شمس r) كلية الهندسة، جامعة عين شمس النس

\section{المسرخلئ}

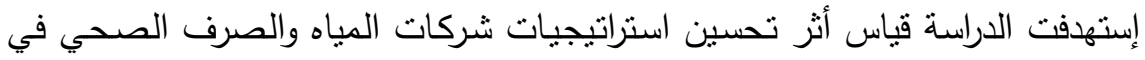

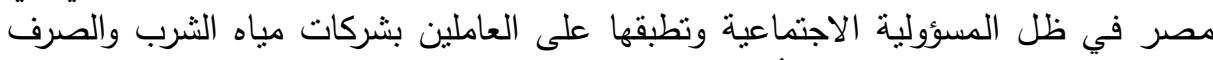

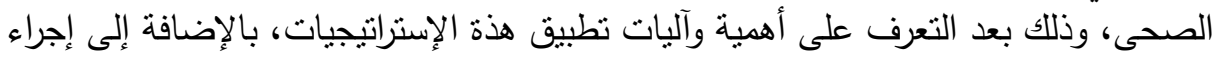

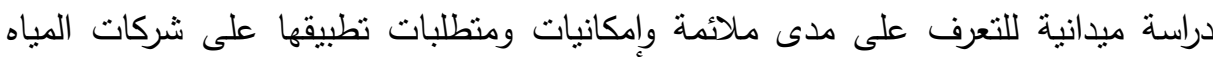
والصرف الصحى المقترحة لهذا التطبيق.

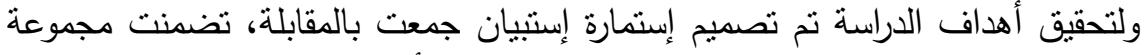

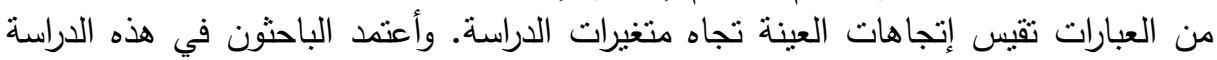

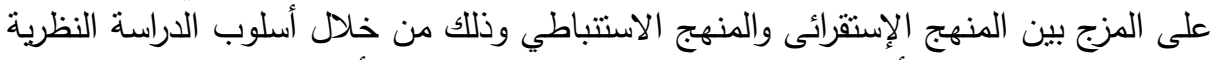
والدراسة الميدانية. وقد أجرى الباحثون تحليل البيانات باستخدام أختبار كروسكال ولاس لإس لكل

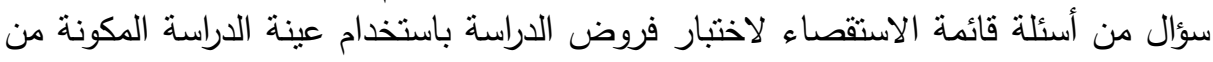

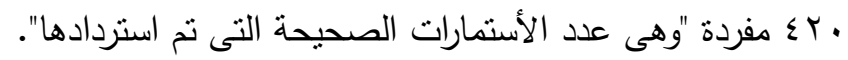

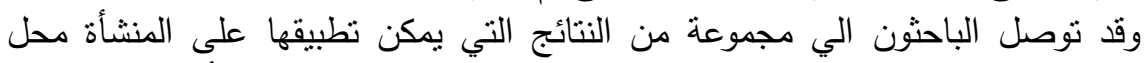

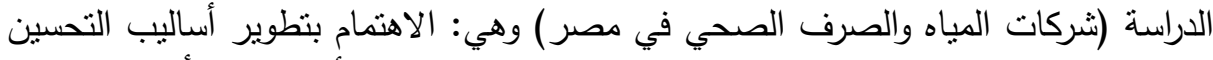

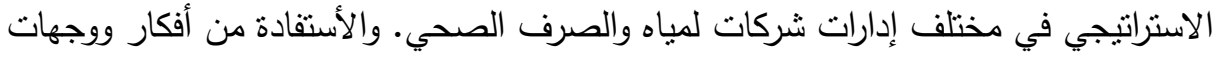

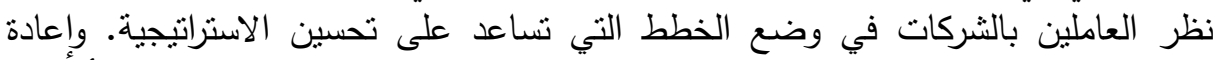

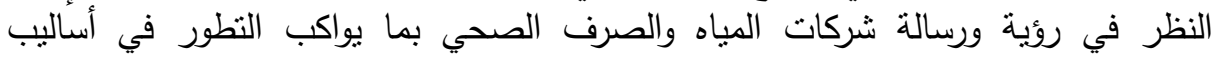
التخطيط والتحسين الحديثة. 
وتوصى الدراسة بضرورة أن يتم الحفاظ على كل المسؤوليات الإجتماعية إتجاه الموظفين

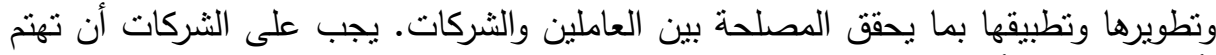
بأن يكون هناك أنشطة تدريبية لزيادة وعى الموظفين بالمسؤولية الإجتماعية.

\section{Mation}

يعد التخطبط الإستراتيجى نوعاً من التخطيط طويل الأجل وهو يتعامل مع المستقبل بطريقة منظمة ومرتبة ومنتابعة، ويغطى كافة الأعمال فى المنظمة ويوضع بعد تحديد أهدافها ومهامها الرئيسية ودراسة نواحى القوى والضعف لديها وتقييم الفرص المتاحة أمامها والقيود التى تحد من نشاطها والتى تظهرها البيئة المحيطة بها، ولذلك بعتبر التخطيط الإستراتيجى

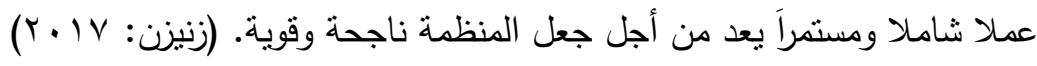
ويتم وضع الخطة الإستراتيجية الرئيسية للمنظمة من خلال إعداد الإستراتيجيات الفرعية لكل وظيفة رئيسية داخل المنظمة مثل (التخطيط التسويقى والتمويلى والإتتاجى) والمحافظه التهنه على البيئة عن طريق الإستخدام الأمنل للموارد الطبيعية. ويقوم التخطيط الإستراتيجى على عدة ركائز أساسية منمنلة فى صياغة رسالة الإسية المنظمة ،ووضع الأهداف الاستراتيجية الهحقة لها، وتحليل البيئة الخارجية لتحديد الفرص المتاحة والتهديدات المحتمله وتوقعات ذوى المصلحة داخل المنظمة وتوليد البدائل الإستراتيجية

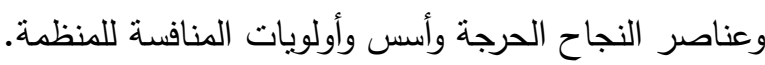
وظهر مفهوم المسئولية الإجتماعية كنتيجة طبيعية للعديد من المظاهر التى ميزت الساحة اقتصادية الدولية والتى من أهمها تفاقم الكوارث البيئية فى السنوات الأخيرة، وأهتمام المنظمات بالجانب الربحى بشكل أساسى وتزايد قضايا الفساد والرشوة فى منظمات الأعمال

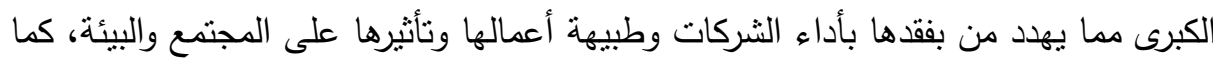
تزايد الضغط من قبل المنظمات غير الحكومية ومنظمات حماية حقوق الإنسان وحماية حقوق العمال، ومنظمات حقوق البيئة وغيرها من المنظمات الأخرى التى تهتم بالجوانب الإنسانية والبيئية والأخلاقية، وهذه الضغوط أثرت بشكل كبير على ممارسات وأنشطة منظمات 
وزاد الالتزام الاجتماعي لاى المؤسسات نتيجة للوعي التقافي والتعليمي وضغوط حركات

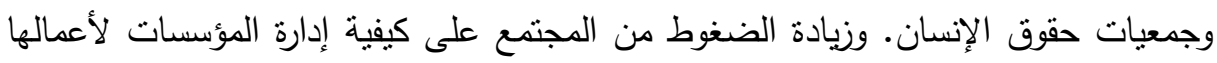
نتيجة الوعي البيئي والإنساني، واستطاعت الكثير من المؤسسات الاجتماعية تحميل الثركات

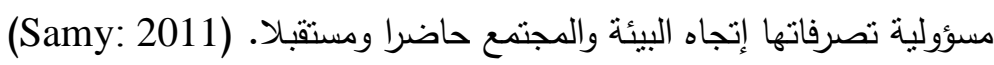
ونظرا لوجود مشكلات كثيرة ارتبطت بإهمال الثركات لمسؤولياتها الاجتماعية وما نجم

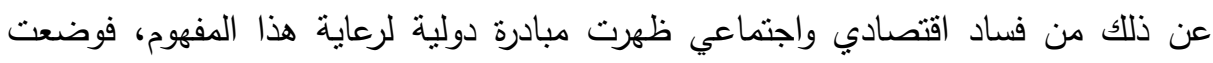

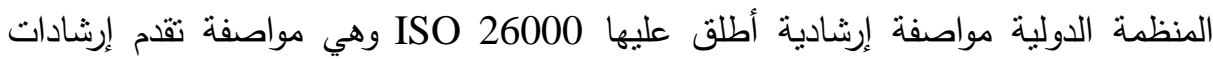
وتوضيحات حول المسؤولية الاجتماعية للمؤسسات، كل هذه العناصر شكلت دوافع لدى مونه

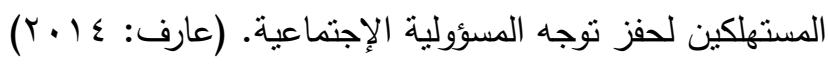

\section{مفحلال السراسة}

تتمنل مشكلة الدراسة فى أن الضغوط الممارسة على المؤسسات الخدمية والصناعية من ناحية الأطراف ذو العلاقة بها، من أجل ضرورة الإلتزام بمسئولياتهم الإجتماعية، وأن التحسين الإستراتيجى يعتبر هى الحل المناسب لمواكبة تطورات وتغيرات المستقبل، وبالرغم من إدراك الإسته

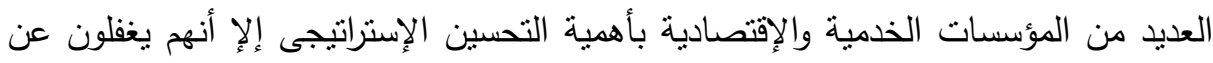

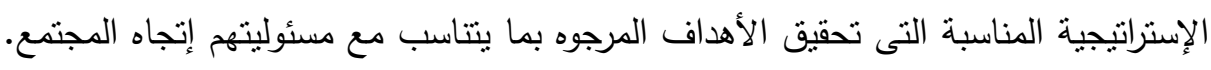

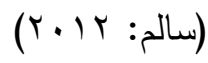

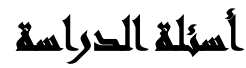

ما أثر تحسين استراتيجيات شركات المياه والصرف الصحي في مصر في ظل المسؤولية الاجتماعية؟ وينبثق من هذا التساؤل الرئيسى التساؤلات الفرعية التالية:

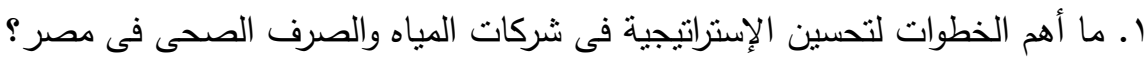


r. ما أهم الإستراتيجيات المستخدمة لتحسين الإستراتيجية الحالية فى ضوء المسؤولية

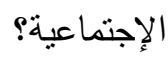

r. ما أثر الإستراتيجية التى تحقق أكبر مكاسب مادية وغير مادية لثركات المياه والصرف

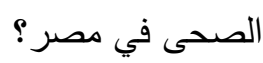

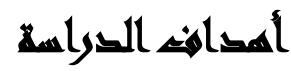

يتمثل الهدف الرئيسى للدراسة فى وضع إطار يوضح إستراتيجيه مقترحه لثركات المياه

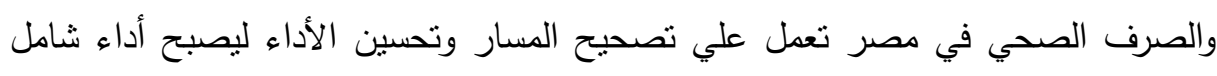

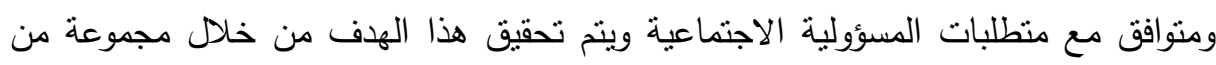

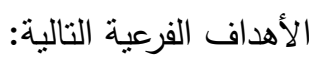
ا. دراسة مدى نأثير الإستراتيجية المقترحة استتتاج مدى إدراج المسؤولية الاجتماعية في

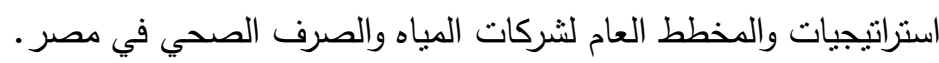

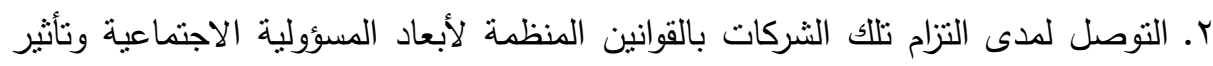
ذلك على المردود المالي لتلك الثركات. r. التعرف على مدى نأثير هذه الأستراتيجية لتحقيق رضى أصحاب المصالح لنتلك الثركات فى ضوء الألتزام بالقوانين المنظمة لأبعاد المسؤولية الاجتماعية.

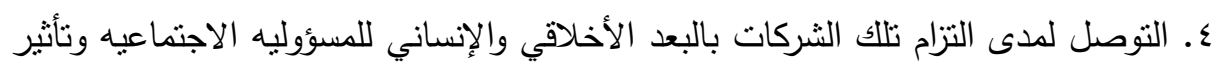
ذللك الميزانيات العامه لها.

ه. معرفة تأثنير الإلتزام بالبعد الأخلاقى والإنسانى على معدلات رضى أصحاب المصالح.

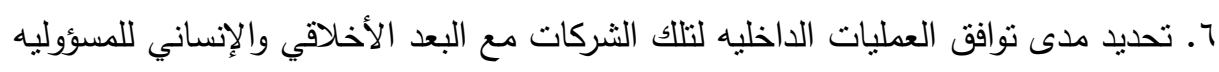

$$
\text { الإجتماعيه. }
$$

V. إدراك مدى تأثير التزام تلك الثركات بالبعد الاقتصادي للمسؤوليه الاجتماعيه على المردود

$$
\text { المالي لها. }
$$

^. تحديد مدى التزام تلك الثركات بالبعد الأقتصادي للمسؤوليه الاجتماعيه وتأثثره على رضى لهى أصحاب المصالح لتلك الثركات. 
9. دراسة الاختلاف بين أراء عينة الدراسة حول متغيرات الدراسة تعزى للمتغيرات الثخصية المتمنلة فى (النوع - السن - المسنوى الوظيفى).

\section{أهمه القواسمة}

تكمن أهميه الدراسة في القيام بتقييم الوضع الراهن لجودة أداء شركات المباه والصرف

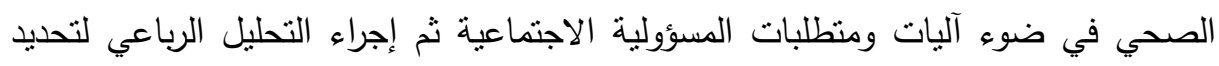

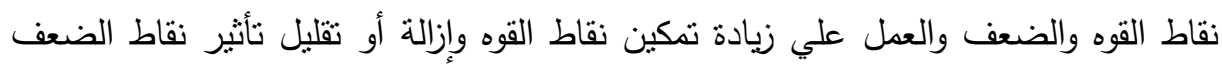
لتلك الثركات وكذلك تحديد الفرص المتاحة لحسن استغلالها والعمل على نلافى التهديدات والتقليل من آنزها وصولا لوضع استراتيجيه للشركات لتحسين منظومة الأداء وفقا لمتطلبات المسؤولية الاجتماعية.

الأهمية العلمية: تكتسب الدراسة أهميتها العلمية من التوجه العالمى للتتمية المستدامة، وبعد ما أصبحت الثركات فى أمس الحاجة إلى الاهتمام بالجوانب الاخلاقية والمسؤولية الاجتماعية

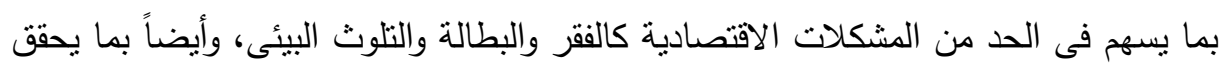

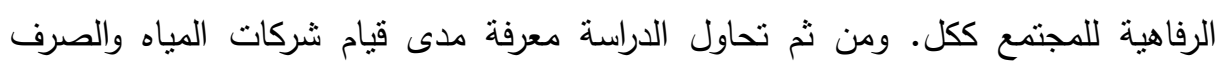

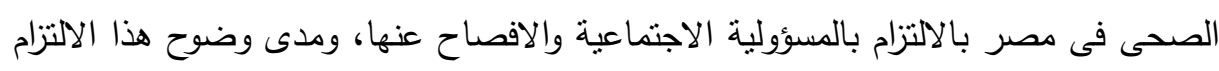

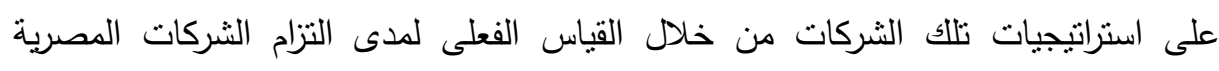

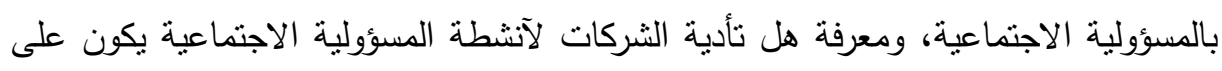

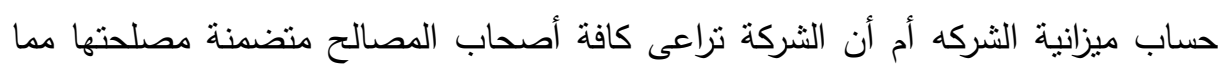
ينعكس إيجابياً على الاداء الاقتصادى للشركة.

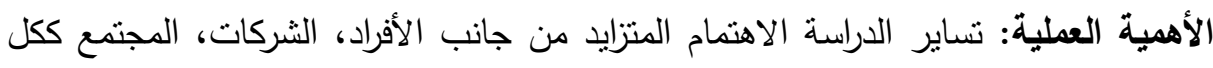

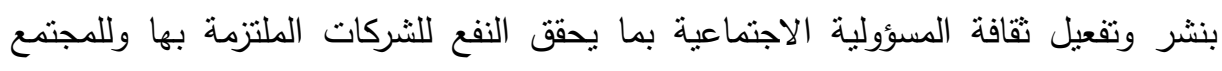

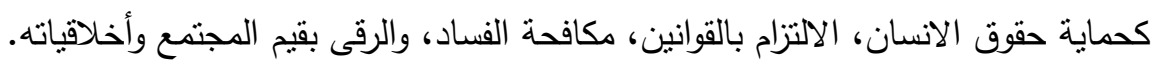




\section{السواسايص السارية}

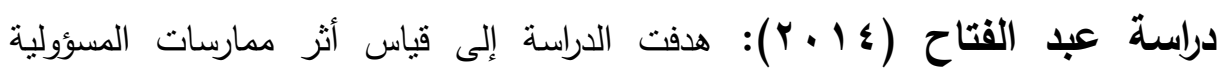

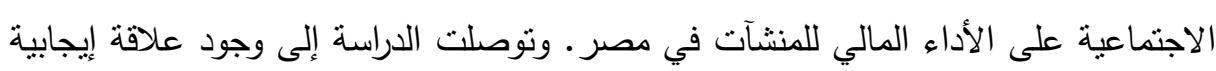

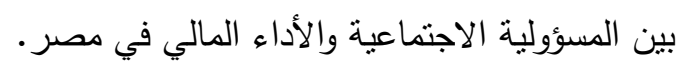

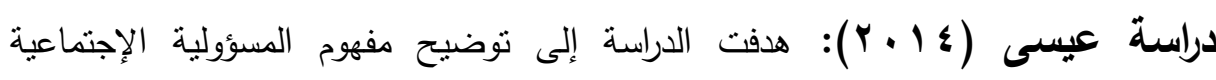

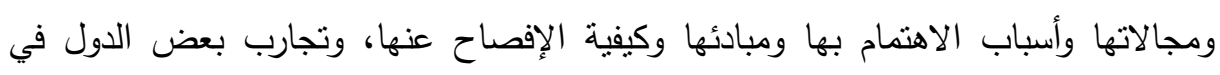

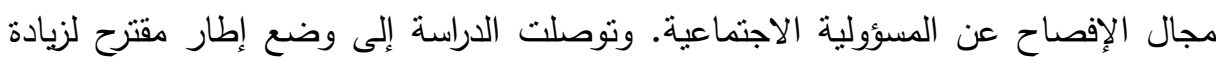

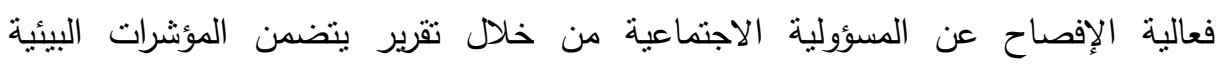
والمؤثرات الاجتماعية والمثاركة الإجتماعية.

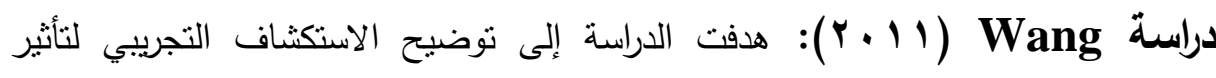

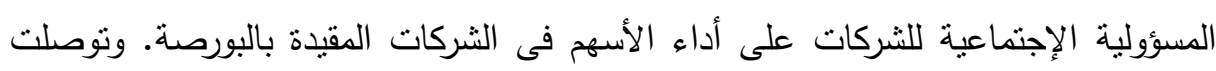

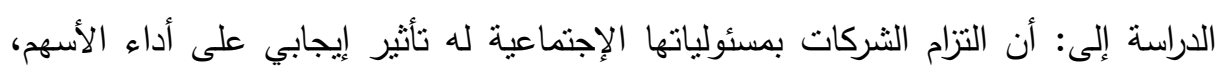

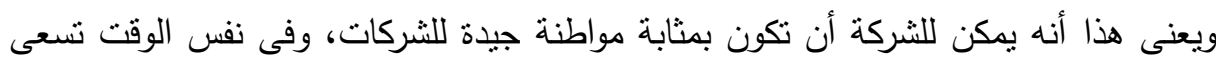

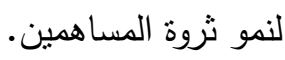

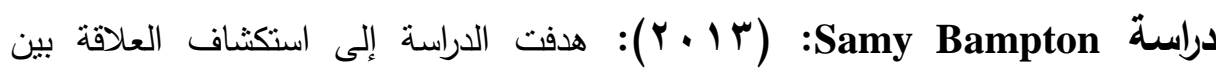

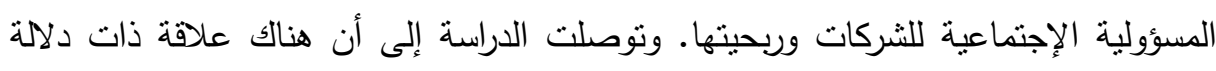
إحصائية إيجابية بين أداء المسؤولية الإجتماعية وربحية الثركة.

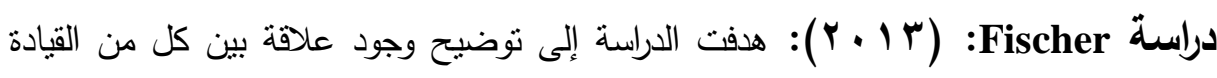
والتخطيط الإستراتيجى وهيكل رأس المال. وتوصلت الدراسة إلى وجود علاقه جوهرية بين القيادة

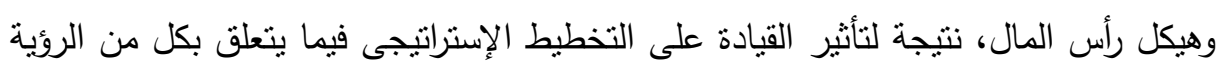

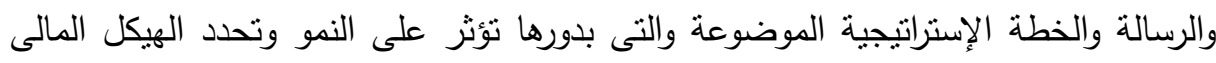
اللمؤسسات التربوية وطبيعة مصادره التمويلية. 


\section{الإطار اللنظيه}

تتمل الدراسة على عدد من المفاهيم التي لابد من توضيحها وتحديد المقصود منها وهي

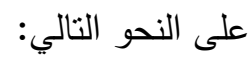

الاستراتيجية: إطار عام مرشد للتفكير والتصرف نتخذه الإدارة العليا، يكون مستمدًا من الأهداف العليا للمنظمة، ليصبح بعد تننيه وسيلة لتحقيق تلك الأهداف وموجها للقرارات المستقبلية التي تتخذها تلك الإدارة في تعبئة مواردها صوب التطوير المستمر لموقفها التتافسي ولئه ولمواطن قوتها من خلال إحداث الموائمة والتكيف مع البيئة الخارجية وصولا إلى ألى أداء (Luxton: 2005) رسالتها.

التخطيط الاستراتيجي: يعرف التخطيط الاستراتيجى على أنه عملية اختيار أهداف المنظمة وتحديد السياسات والإستراتيجيات اللازمة لتحقيق الأهداف وتحديد الأساليب الضرورية لضمان تتفيذ السياسات والإستراتيجيات الموضوعة. ويمثل التخطيط الإستراتيجي العطلية التخطيطية طويلة المدى التي يتم إعدادها بصورة رسمية لتحديد وتحقيق أهداف المنظمة (Szymanska: 2011). وعرفها أخر بأنها: "تخطيط طويل الأجل مرنبط بتحديد اتجاه المنظمة فى المستقبل في

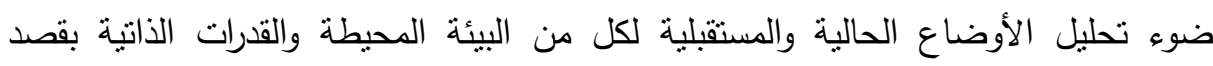
تحقيق مسار رئيسى واضح على مستوى المنظمة ككل من ناحية الوحدات الوظيفية أو

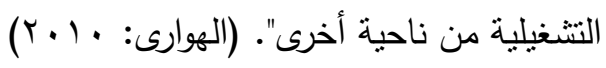

وأضاف (Kenneth: 1990) التخطيط الإستراتيجى بأنه: "طريقة نجاح المنظمة من خلا إطار عملى يتضمن التقكير الإستراتيجى والرؤية المستقبلية لترشيد قرارات المنظمة". ويعرف التخطيط الاستراتيجي "أنه العملية التي تتضمن أتخاذ القرارات التي تربط بين الأهداف

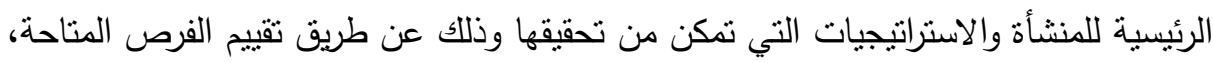

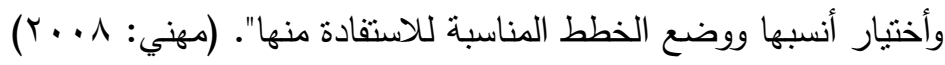


وعرف أخر التخطيط الإستراتيجي بأنه: "أول جزء من الإدارة الإستراتيجية وهو ما يتعلق

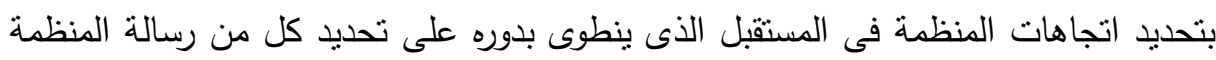
وأهدافها بناء على تحليل الوضع الحالى والمستقبلى لكل من البيئة المحيطة والقدرات الذاتية.

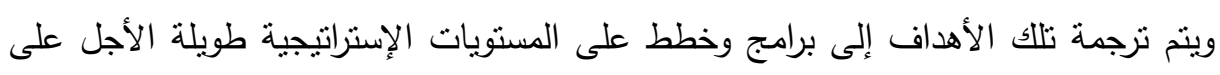

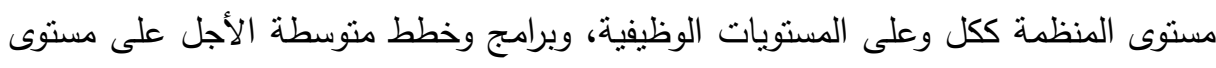

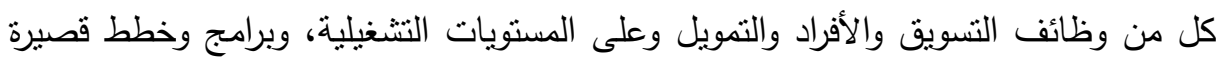

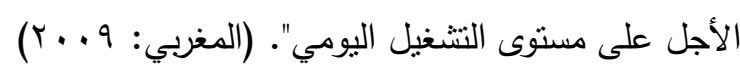
تعريف المسئولية الإجتماعية: المسؤولية الاجتماعية هى مجموعة الواجبات أو التصرفات التي تقوم بها المنظمة من خلال قراراتها بزيادة رفاهية المجتمع والعناية بمصالحة الإنية

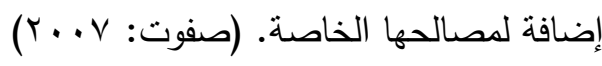
وأضاف أخر : أن المسؤولية الإجتماعية للشركات ليست نوعاً من الإحسان، بل هي

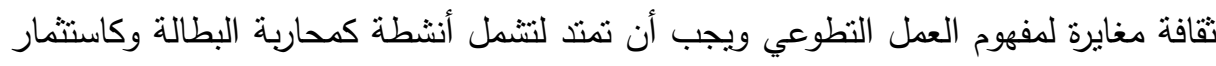
جيد لتحسين صورة الثركات في المجتمع وأن يكون لها علاقة بالأهداف التتموية. (يونس:

وأنشار أخر: أن المسؤولية الإجنماعية بأنها: قيام منظمات الأعمال بتتفيذ الأنشطة

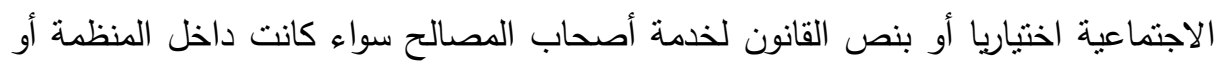

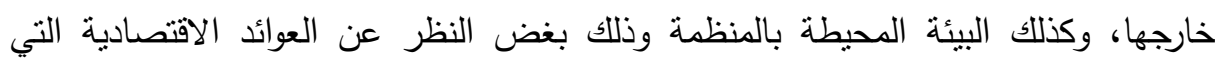

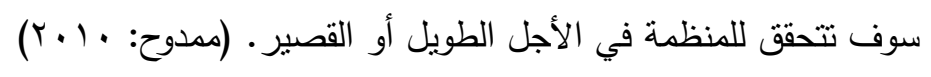

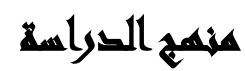

فى ضوء طبيعة المشكلة وهدف وأهمية الدراسة أعتمد الباحث على منهجين أساسيين فى إعداد الدراسة هما:

المنهج الوصفي التحليلي: حيث قام الباحثون بالإطلاع وإستقراء الدراسات العلمية التى تتاولت موضوع الدراسة من خلال إنباع أسلوب الدراسة المكتبية والإطلاع على المراجع العلمية المتخصصة العربية والأجنيية من كتب علمية ومقالات منشورة بالمجلات العلمية

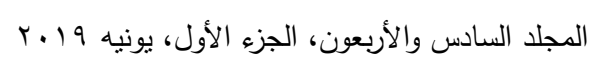


المحكمة والدوريات المختلفة وما صدر من المؤتمرات العلمية ورسائل علمية والدراسات السابقة وأبحاث مرتبطة بموضوع الدراسة والمتعلقة بالمشكلة موضوع الدراسة. المنهج التطبيقى: أستخدم الباحث هذا المنهج بهدف الكثف عن النتائج المنطقية المترتبة على إختبار الفروض الأساسية للاراسة، وذلك من خلال القبام بدراسة ميدانية تهدف إلى

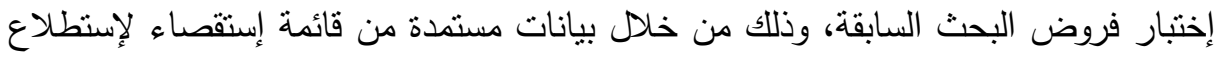

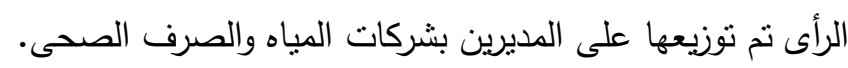

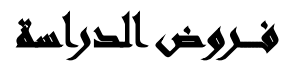

من أجل تفسير إثكالية الدراسة ومحاولة الإجابة عن الأسئلة المطروحة يمكن صياغة

الفرضيات التالية:

الفرض الأول: لا يوجد أثز جوهري للبعد القانونى كأحد أبعاد المسئولية الاجتماعية على الإستراتيجية المالية.

الفرض الثانى: لا يوجد أثز جوهري للبعد الاخلاقى كأحد أبعاد المسئولية الاجتماعية على الإنى الإستراتيجية التسويقية البيئية. الفرض الثالث: لا يوجد أثر جوهري للبعد الاقتصادى كأحد أبعاد المسئولية الاجتماعية على الإستراتيجية الانتاجية البيئية.

\section{إجبراعايت التصاسة}

الاراسة الميدانية (المنهج التحليلي): اعتمد الباحثون في إجراء الدراسة الميدانية على

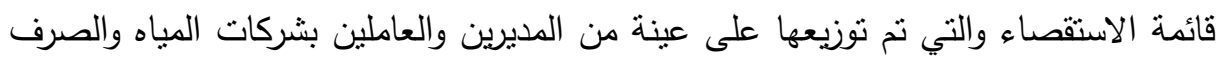

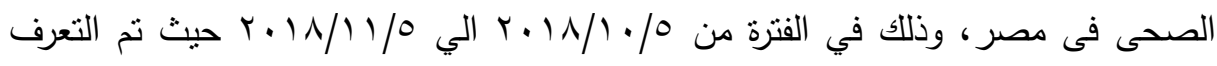
على أراءهم ورغباتهم واتجاهاتهم والعناصر الغير مرضية التى تواجههم وانطباعاتهم 
واقتراحاتهم، وقد تم استخدام الأساليب الإحصائية في تحليل البيانات والمعطيات التي تم

وقد توصلت الدراسة إلى وجود فجوة بحثية لم تغطيها العديد من الدراسات السابقة، ومن

ثم أهتمت الدراسة بإجراء دراسة إستكثافية في المجال التطبيقي، ثم تم استعراض نتائج الدراسة

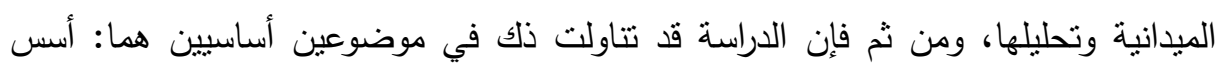

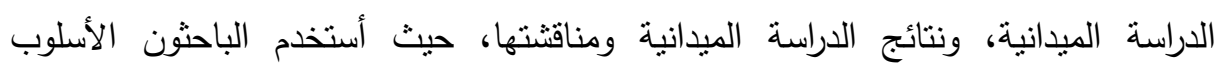
الإحصائي الأنسب للتحليل، وهو أختبار كروسكال ولاس، ولما كانت البيانات قد جاءت التهات

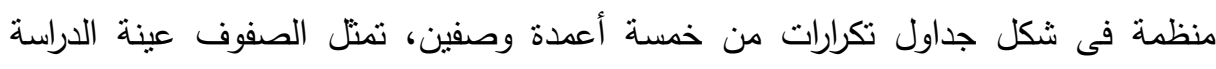
(المديرين بشركات المياه والصرف الصحى) وتمثل الأعمدة استجابات الأفراد على أسئلة الاستقصاء والتى نم ترتيبها نتازلياً من موافق تماماً إلى لا أوافق مطلقاً.

\section{أسلورب وأسوايت الترواسة}

بمكن توضيح كلاً من مجتمع وعينة الدراسة كما يلي:

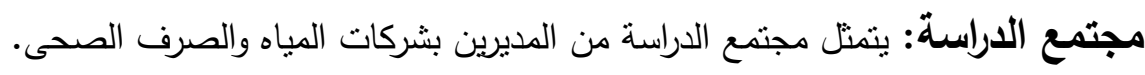

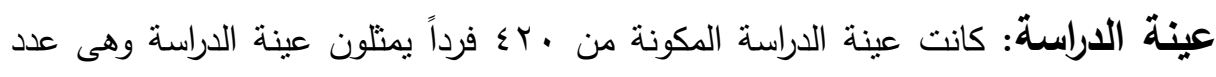
الاستمارات الصحيحة التى تم استردادها من (المديرين بشركات المياه والصرف الصحى).

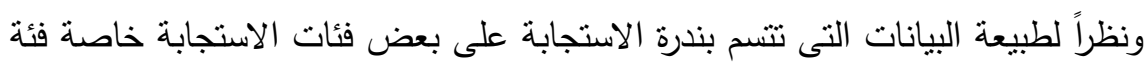
لا أوافق مطلقاً، فقد قام الباحثون بحساب قيمة كروسكال ولاس بإستخدام برنامج

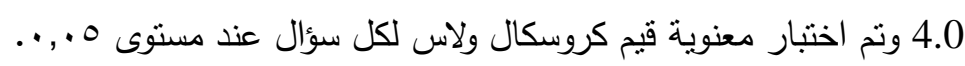

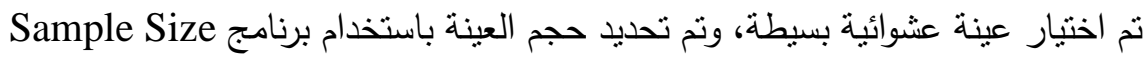
\% 9alculator

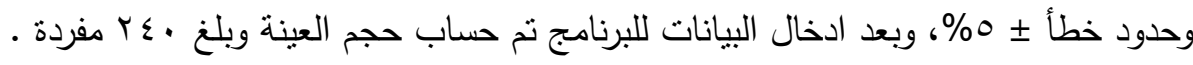
اعتمد الباحثون على الأساليب التالية: وحثل

معامل الثبات ألفا كرونباخ: ويستخدم لحساب معامل الثبات، وذلك لبحث مدى إمكانية الاعتماد على نتائج الدراسة الميدانية فى تعميم النتائج وقد كانت قيمة الفا لابعاد المقياس لبعل 
(

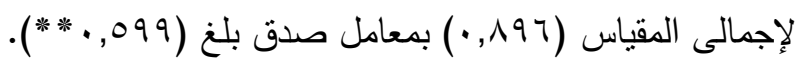
قياس متغيرات الدراسة: في ضوء الدراسات السابقة التي إطلع عليها الباحثون، فقد اعتمد الباحثون فى قياس المتغير المستقل (تحسين الإستراتيجيات) والمتغير التابع (المسؤولية الإجتماعية).

أداة تجميع بيانات الدراسة الميدانية: قام الباحثون بتصميم قائمة استقصاء لتجميع البيانات من مفردات البحث، حيث مر إعدادها وتصميمها بالخطوتين التاليتين: الخطوة الأولى: إعداد قائمة الاستقصاء فيى صورتها الأولية: وصف عينة الدراسة: تم إجراء الدراسة علي عدد م شركة نابعه حيث نم إجراء الاستقصاء

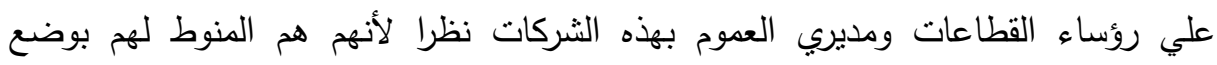

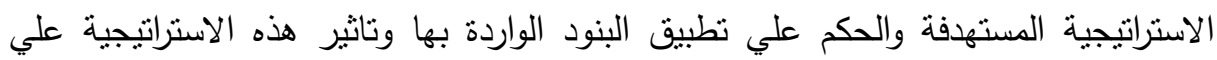

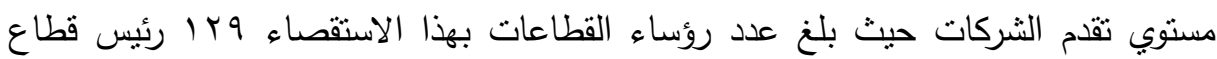
بينما بلغ عدد مديري العموم O19 مدير عام بهذه الشركات كما هو موضح بالاتي: 
وصف عينة الدراسة:

\begin{tabular}{|c|c|c|c|c|c|c|c|c|}
\hline \multirow{2}{*}{ 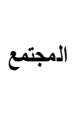 } & \multicolumn{2}{|c|}{ العدد الدوارد } & \multicolumn{2}{|c|}{ العدد المطلوب عمل استقصاء له } & \multicolumn{2}{|c|}{ 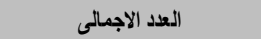 } & \multirow{2}{*}{ اسم الشركة } & \multirow{2}{*}{ p } \\
\hline & مديرى العموم & رؤساء القطاعات & | مديرى العموم & رؤساء القطاعات & | مديرى العموم | مام & رؤساء القطاعات | & & \\
\hline 83 & 22 & 5 & 35 & 7 & 70 & 13 & شركة مياه القاهرة & 01 \\
\hline 40 & 12 & 2 & 17 & 3 & 34 & 6 & شركة الغريية & 02 \\
\hline 53 & 16 & 3 & 22 & 5 & 44 & 9 & شركة قنـا & 03 \\
\hline 78 & 20 & 3 & 34 & 6 & 67 & 11 & شركة الثرقية & 04 \\
\hline 55 & 17 & 3 & 24 & 4 & 47 & 8 & شركة القليوبية & 05 \\
\hline 101 & 33 & 6 & 43 & 8 & 85 & 16 & شركة الاقهلية & 06 \\
\hline 71 & 20 & 4 & 29 & 7 & 58 & 13 & شركة سو هاج & 07 \\
\hline 59 & 16 & 4 & 24 & 6 & 48 & 11 & شركة كفر الثيخ & 08 \\
\hline 31 & 9 & 2 & 13 & 3 & 25 & 6 & شركة البحر الاحمر & 09 \\
\hline 52 & 14 & 4 & 22 & 5 & 43 & 9 & شركة مياه الاسكندرية & 10 \\
\hline 50 & 13 & 3 & 21 & 5 & 41 & 9 & شركة هدن القتاه & 11 \\
\hline 56 & 13 & 2 & 25 & 4 & 49 & 7 & شركة صرف القاهرة & 12 \\
\hline 42 & 11 & 3 & 16 & 5 & 32 & 10 & شركة أسوان & 13 \\
\hline 90 & 11 & 6 & 36 & 9 & 72 & 18 & شركة الجيزة & 14 \\
\hline 37 & 10 & 2 & 15 & 4 & 30 & 7 & شركة الاقصر & 15 \\
\hline 48 & 12 & 3 & 20 & 5 & 39 & 9 & شركة مطروح & 16 \\
\hline 38 & 10 & 2 & 16 & 3 & 32 & 6 & شركة المنوفية & 17 \\
\hline 43 & 12 & 3 & 18 & 4 & 35 & 8 & شركة الفيوم & 18 \\
\hline 48 & 12 & 5 & 18 & 7 & 35 & 13 & شركة البحيرة & 19 \\
\hline 63 & 17 & 4 & 26 & 6 & 51 & 12 & شركة دمياط & 20 \\
\hline 44 & 12 & 3 & 18 & 5 & 35 & 9 & شركة المنيا & 21 \\
\hline 55 & 16 & 3 & 24 & 4 & 48 & 7 & شركة أسيوط & 22 \\
\hline 40 & 11 & 2 & 17 & 4 & 33 & 7 & شركة بنى سويف & 23 \\
\hline 82 & 24 & 4 & 36 & 5 & 72 & 10 & شركة صرف الاسكنرية & 24 \\
\hline 48 & 13 & 3 & 20 & 5 & 39 & 9 & شركة شمال وجنوب سيناء & 25 \\
\hline 1407 & 376 & 84 & 589 & 129 & 1164 & 243 & & \\
\hline
\end{tabular}


مجلة العلوم البيئية

معهد الدراسات والبحوث البيئية - جامعة عين شمس به

جدول (1) يوضح إجمالي مجتمع الدراسة وعينة الدراسة

\begin{tabular}{|c|c|c|c|}
\hline النسبة \% & التكرار & & \\
\hline$V \varepsilon, 1$ & TYV & ذكر & \multirow{3}{*}{ النوع } \\
\hline$T_{0,9}$ & 19 & انثى & \\
\hline $1 \ldots$ & $r .7$ & إجمالي & \\
\hline$r \cdot, r$ & $7 Y$ & رؤساء القطاعات & \multirow{3}{*}{ لمسمي الوظيفي } \\
\hline$\vee 9,1$ & $r \leq$. & مديرو العموم & \\
\hline $1 \ldots$ & $r .7$ & إجمالي & \\
\hline
\end{tabular}

كما يتضح من الجدول السابق وصف عينة الدراسة وتوزيعها من حيث النوع حيث تكونت

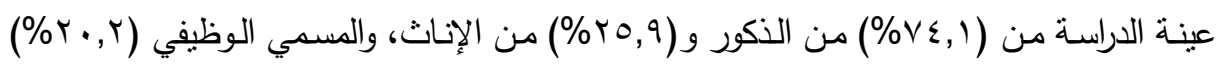

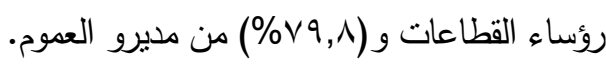

الخطوة الثانبة: استبفاء بيانات قوائم الاستقصاء وإعدادها للتحليل الحصائي: قام الباحثون فى هذه المرحلة باستيفاء بيانات قوائم الاستقصاء من مفردات الدراسة بعد أن تم إعدادها فى صورتها النهائية بعد استبعاد بعض العبارات التي لم يثبت صدقها وثباتها، حيث قام الباحث بالتوجه إلى بعض الثركات قيد الدراسة لعرض قوائم الاستقصاء على بعض المديرين عن طريق المقابلات الثخصية التى أجرتها معهم. هذا كما نم مراجعة قوائم الاستقصاء بعد أن تمت الإجابة عليها، ثم قام الباحثون بإدخال

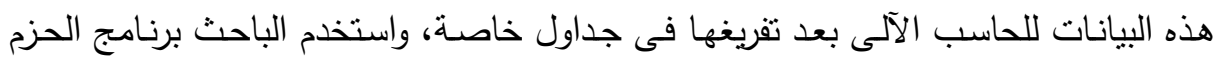
الإحصائية (SPSS . V25) فى إجراء التحليل الإحصائى لبيانات الدراسة الميدانية، وذلك هلك بالاستعانة بمكتب متخصص بالدراسات والتحليل الإحصائي. أساليب التحليل الإحصائي: أسلوب الانحدار المتعدد: ويستخدم لحساب معاملات الانحدار المتعدد المتغير المستقل مع الإع

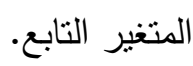
اختبار كروسكال ـولاس "Kruskal Walias Test: أحد الاختبارات اللامعلمية التي تستخدم لاختبار الفرق بين منوسطين. 
إن أنسب الاختبارات الإحصائية لهذا الثكل من البيانات هو اختبار كروسكال ـولاس Kruskal Walias Test"

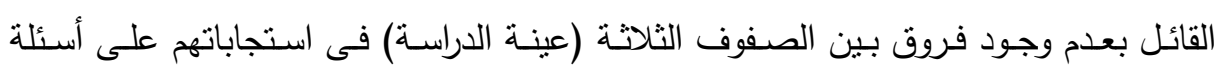

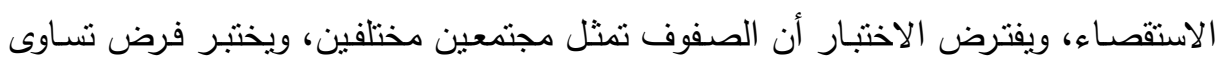

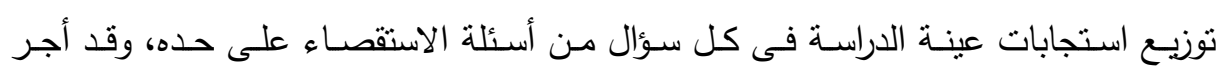

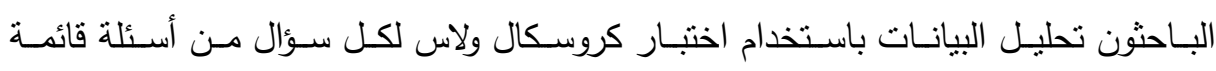
الاستقصاء لاختبار فروض الدراسة. الفرضية الأولي: لا يوجد أثر جوهري للبعد القانونى كأحد أبعاد المسئولية الاجتماعية على الإستراتيجية المالية.

الفرضية الفرعية الثانية:لا يوجد أثز جوهري للبعد الاخلاقى كأحد أبعاد المسئولية الاجتماعية على الإستراتيجية التسويقية البيئية. الفرضية الفرعية الثالثة:لا يوجد أثز جوهري للبعد الاقتصادى كأحد أبعاد المسئولية الاجتماعية على الإستراتيجية الانتاجية البيئية. الفرضية الأولي:لا يوجد اثر جوهري للبعد القانونى كأحد أبعاد المسئولية الاجنماعية على الإنى الإستراتيجية الانتاجية البيئية. 
جدول (ץ): نموذج الانحدار الخطي لتحديد معنوية تأثير البعد القانونى كأحد أبعاد المسئولية الاجتماعية على الإستراتيجية المالية Model Summary

\begin{tabular}{|c|c|c|c|c|c|c|}
\hline \multicolumn{3}{|c|}{ Std. Error of the Estimate } & \begin{tabular}{|c} 
Adjusted R \\
Square
\end{tabular} & $\begin{array}{c}\mathbf{R} \\
\text { Square }\end{array}$ & $\mathbf{R}$ & Model \\
\hline \multicolumn{3}{|c|}{$\cdot, \Sigma \wedge r \curlyvee \wedge$} & $\cdot, 1 \leq 0$ & $\cdot, 1 \leq V$ & ar人r. & 1 \\
\hline \multicolumn{3}{|c|}{$\cdot, \varepsilon 7 \cdot 7 r$} & $\cdot, Y Y$ & • & $b \leq V Y$. & r \\
\hline \multicolumn{7}{|c|}{ ANOVAc } \\
\hline Sig. & $\mathbf{F}$ & Mean Square & df & $\begin{array}{l}\text { Sum of } \\
\text { Squares }\end{array}$ & \multicolumn{2}{|c|}{ Model } \\
\hline \multirow[t]{3}{*}{$a \cdots \cdot$} & $\vee \wedge, Y \leq$ & $|\wedge, r q|$ & 1 & $|\wedge, r q|$ & Regression & \multirow{3}{*}{1} \\
\hline & & • & $\varepsilon 0 \wedge$ & $1 \cdot 7,047$ & Residual & \\
\hline & & & $£ 09$ & $|r \varepsilon, \wedge| V$ & Total & \\
\hline \multirow[t]{3}{*}{$\mathrm{b} \cdots \cdot$} & 70,7rT & $1 r, 9 Y 4$ & r & rV,A०r & Regression & \multirow{3}{*}{ r } \\
\hline & & $\cdot, Y, r$ & ¿OV & 97,970 & Residual & \\
\hline & & & $\leqslant 09$ & $|r \varepsilon, \Lambda| V$ & Total & \\
\hline \multicolumn{7}{|c|}{ Coefficientsa } \\
\hline \multirow{2}{*}{ Sig. } & \multirow[t]{2}{*}{$\mathbf{t}$} & $\begin{array}{c}\text { Standardized } \\
\text { Coefficients }\end{array}$ & \multicolumn{2}{|c|}{$\begin{array}{c}\text { Unstandardized } \\
\text { Coefficients } \\
\end{array}$} & \multirow{2}{*}{\multicolumn{2}{|c|}{ Model }} \\
\hline & & Beta & Std. Error & $\mathbf{B}$ & & \\
\hline$\cdot$ & $1 \leq, Y \backslash \leq$ & & $\cdot, \Sigma \Gamma$ & $7,1 \times 9$ & (Constant) & \multirow{2}{*}{1} \\
\hline - & $\wedge, \wedge \neg \wedge-$ & 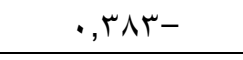 & $\cdot, 110$ & $1,7 r v-$ & $\mathrm{X} 3$ & \\
\hline . & $1 \cdot, 1 K \pi$ & & $\cdot, \varepsilon 7 T$ & $\varepsilon, \uparrow \wedge \wedge$ & (Constant) & \multirow{3}{*}{ r } \\
\hline$\cdot$ & $\wedge, \cdot \wedge 1-$ & •,r世人- & $\cdot, 1 \vee 9$ & $1, \varepsilon \varepsilon r-$ & $\mathrm{X} 3$ & \\
\hline$\cdot$ & $7, V \backslash T$ & $\cdot, Y \wedge$ & $\therefore, 1 \wedge 9$ & $\cdot, 091$ & $\mathrm{X} 1$ & \\
\hline
\end{tabular}

\section{a. Dependent Variable: Y1}

$$
\text { يتضح من الجدول السابق مجموعة من النتائج التي تم التوصل إليها: }
$$

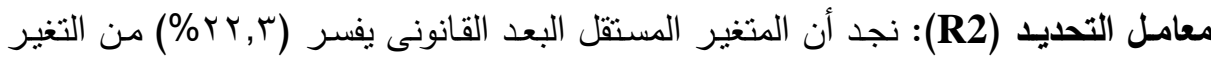
الكلي في المتغير التابع (الإستراتيجية المالية). وباقي النسبة يرجع إلى الخطأ العشوائي في

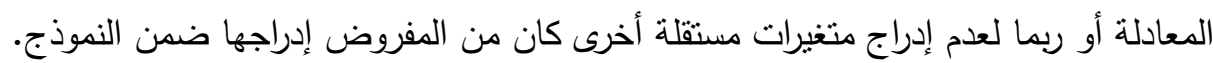

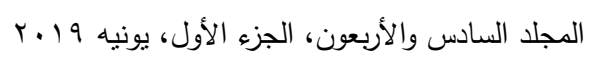




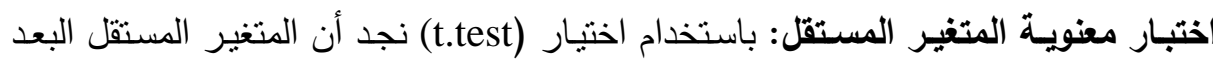

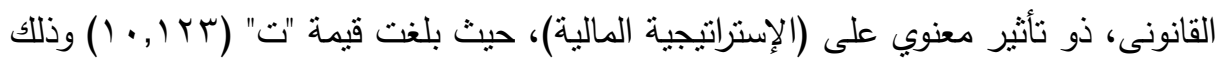

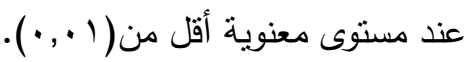
اختبار معنوية جودة توفيق نموذجة الاتحدار: لاختبار معنوية جودة توفيق النموذج ككل، تم

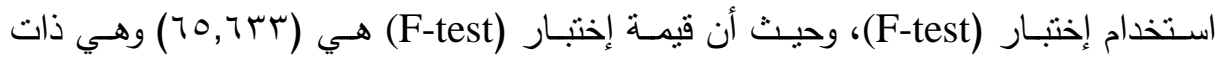

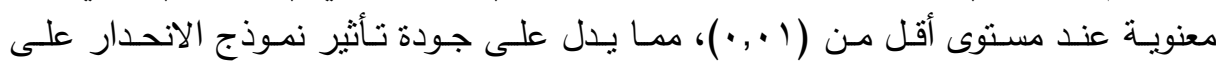
الإستراتيجية المالية. معادلة النموذج: وهذا يعنى أنه يمكن تقدير Y1 بقدره تقسيرية r, r Y Y كما يلى : $\mathrm{Y} 1=4.688-1.443 \mathrm{X} 3+0.598 \mathrm{X} 1$

$$
\text { فيما يلى مخرجات تشغيل البيانت الخاصة بمحدات Y2 : }
$$

الفرضية الفرعية الثانية: لا يوجد اثر جوهري للبعد الاخلاقى كأحد أبعاد المسئولية الاجتماعية على الإستراتيجية التسويقية البيئية. جدول (ץ): نموذج الانحدار الخطي لتحديد معنوية تأثير البعدالاخلاقى كأحد أبعاد المسئولية الاجتماعية على الإستراتيجية النسويقية البيئية

\begin{tabular}{|c|c|c|c|c|c|c|c|c|c|}
\hline \multicolumn{10}{|c|}{ Model Summary } \\
\hline \multicolumn{3}{|c|}{ Std. Error of the Estimate } & \multicolumn{3}{|c|}{ Adjusted R Square } & \multicolumn{2}{|c|}{ R Square } & $\mathbf{R}$ & Model \\
\hline \multicolumn{3}{|c|}{., $19 \vee \vee r$} & \multicolumn{3}{|c|}{$\cdot, 1 \leq \varepsilon$} & \multicolumn{2}{|c|}{$\cdot, 1 \leq 7$} & $a, r \wedge r$ & 1 \\
\hline \multicolumn{3}{|c|}{$\cdot, \wedge \wedge \mid \wedge$} & \multicolumn{3}{|c|}{$\cdot$, rYo } & \multicolumn{2}{|c|}{$\cdot$, YrA } & ${ }^{b} \cdot, £ \vee \wedge$ & $r$ \\
\hline \multicolumn{3}{|c|}{., $1 \wedge r \vee q$} & \multicolumn{3}{|c|}{$\cdot, Y 41$} & \multicolumn{2}{|c|}{$\cdot$, rqo } & ${ }^{c} \cdot, 010$ & $r$ \\
\hline \multicolumn{10}{|c|}{ ANOVAd } \\
\hline Sig. & $\mathbf{F}$ & \multicolumn{2}{|c|}{ Mean Square } & df & \multicolumn{2}{|c|}{ Sum of Squares } & \multicolumn{3}{|c|}{ Model } \\
\hline \multirow[t]{3}{*}{ a.,... } & $\vee \wedge$, Y०Y & \multicolumn{2}{|l|}{$r, \cdot \pi r$} & 1 & \multicolumn{2}{|c|}{$r, .7 r$} & \multicolumn{2}{|c|}{ Regression } & \multirow{3}{*}{1} \\
\hline & & \multirow{2}{*}{\multicolumn{2}{|c|}{$\cdot, \cdot r q$}} & $\leqslant 0 \wedge$ & \multicolumn{2}{|c|}{$18,9.7$} & \multicolumn{2}{|c|}{ Residual } & \\
\hline & & & & $\leqslant 09$ & \multicolumn{2}{|c|}{$r \cdot, q V$} & \multicolumn{2}{|r|}{ Total } & \\
\hline \multirow[t]{3}{*}{ b.,... } & $7 V, 09 \leq$ & $r, r q \leq$ & & $r$ & \multicolumn{2}{|c|}{$\varepsilon, \vee \wedge \vee$} & \multicolumn{2}{|c|}{ Regression } & \multirow{3}{*}{ r } \\
\hline & &.,$\cdot r_{0}$ & & $\leqslant 0 V$ & 17,11 & & & esidual & \\
\hline & & & & $\leqslant 09$ & $r \cdot, q$ & & & Total & \\
\hline \multirow[t]{3}{*}{$c, \ldots$} & D\&,qur & 1,104 & & $r$ & 0,07 & & Regr & ression & \multirow{3}{*}{$r$} \\
\hline & & •, & & 纟04 & $10, \varepsilon$. & & Res & sidual & \\
\hline & & & & $\leqslant 09$ & $r \cdot q$ & & & otal & \\
\hline
\end{tabular}


تايع جدول (ץ): نموذج الانحدار الخطي لتحديد معنوية تأثير البعدالاخلافى كأحد أبعاد

المسئولية الاجتماعية على الإستراتيجية التسويقية البيئية

\begin{tabular}{|c|c|c|c|c|c|c|}
\hline \multicolumn{7}{|c|}{ Coefficientsa } \\
\hline \multirow[t]{2}{*}{ Sig. } & \multirow[t]{2}{*}{$\mathbf{t}$} & \multirow{2}{*}{$\begin{array}{c}\text { Standardized } \\
\text { Coefficients }\end{array}$} & \multicolumn{2}{|c|}{$\begin{array}{c}\text { Unstandardized } \\
\text { Coefficients }\end{array}$} & \multirow{2}{*}{\multicolumn{2}{|c|}{ Model }} \\
\hline & & & Std. Error & B & & \\
\hline - & 10,10 & & r & $\cdot, 901$ & (Constant) & \multirow{2}{*}{1} \\
\hline . & $\Lambda, \wedge \circ Y$ & $\cdot, r \wedge r$ & $\cdot, \cdot \mathrm{r \Lambda}$ & צ & X1 & \\
\hline - & $11,7 \vee V$ & & $\cdot, 1 \wedge 9$ & $r, r, q$ & (Constant) & \multirow{3}{*}{ r } \\
\hline - & $\Lambda, .0 \leqslant$ & ט טr, & $\cdot, \cdot 47$ & $\cdot, r q r$ & X1 & \\
\hline - & $7,9 \vee \vee-$ & - ,rq- & $\cdot, \cdot V r$ & $\cdot, 0.9-$ & $\mathbf{X 3}$ & \\
\hline . & 11,07 & & $\cdot, 1 \wedge 0$ & $r, 1 \leq r$ & (Constant) & \multirow{4}{*}{$r$} \\
\hline - & $9,0 \leq r$ & •, $\{0 r$ & $\cdot, \cdot \leq 1$ & צ & X1 & \\
\hline · & $\vee, \wedge, ०-$ & $\cdot, 71 \leq-$ & $\cdot, 1 \mathrm{rA}$ & $1, \cdot 8^{4}-$ & $\mathbf{X 3}$ & \\
\hline$\cdot$ & $\varepsilon, \wedge \cdot \varepsilon$ & $\cdot, \leqslant 1$ & $\cdot, 1+q$ & $\cdot, \mathrm{TV}$ & $\mathrm{X} 2$ & \\
\hline
\end{tabular}

يتضح من الجدول السابق مجموعة من النتائج التي تم التوصل إليها:

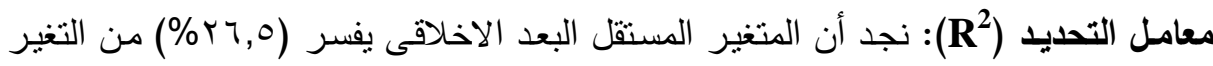

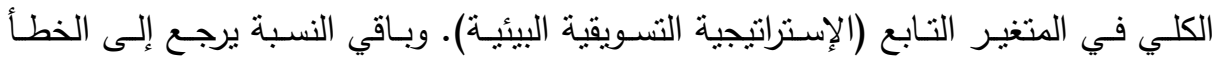

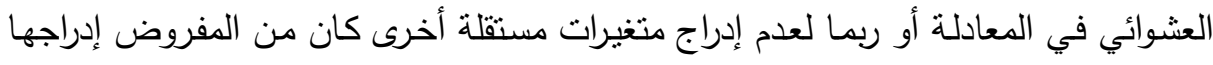
ضنمن النموذج. اختبار معنويـة المتغير المستقل: باستخدام اختبار (t.test) نجد أن المتغير المستقل البعد

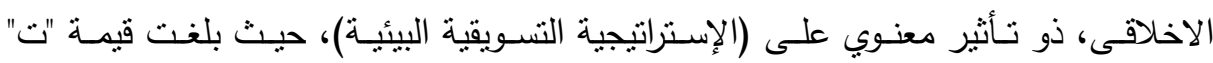

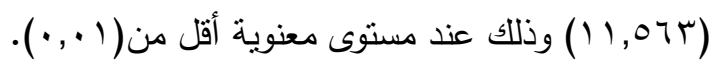
اختبار معنوية جودة توفيق نموذج الانحدار: لاختبار معنوية جودة نوفيق النموذج ككل، تم

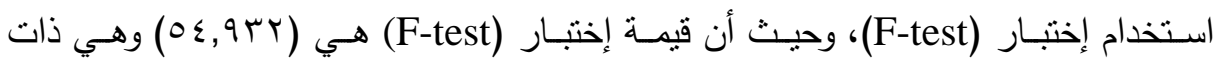




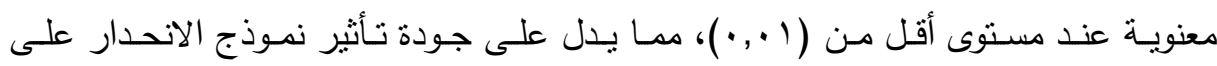
الإستراتيجية التسويقية البيئية.

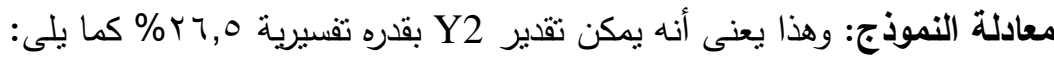
$\mathrm{Y} 2=2.143+0.396 \mathrm{X} 1-1.076 \mathrm{X} 3$ + $0.670 \mathrm{X} 2$

$$
\text { فيما يلى مخرجات تتغيل البيانت الخاصة بمحددات Y3: }
$$

الفرضية الفرعية الثالثة: لا يوجد أثز جوهري للبعد الاقتصادى كأحد أبعاد المسئولية الاجتماعية على الإستراتيجية الإنتاجية البيئية. جدول (§): نموذج الانحدار الخطي لتحديد معنوية تأثثر الاقتصادى كأحد أبعاد المسئولية الاجتماعية على الإستراتيجية الإنتاجية البيئية

\section{Model Summary}

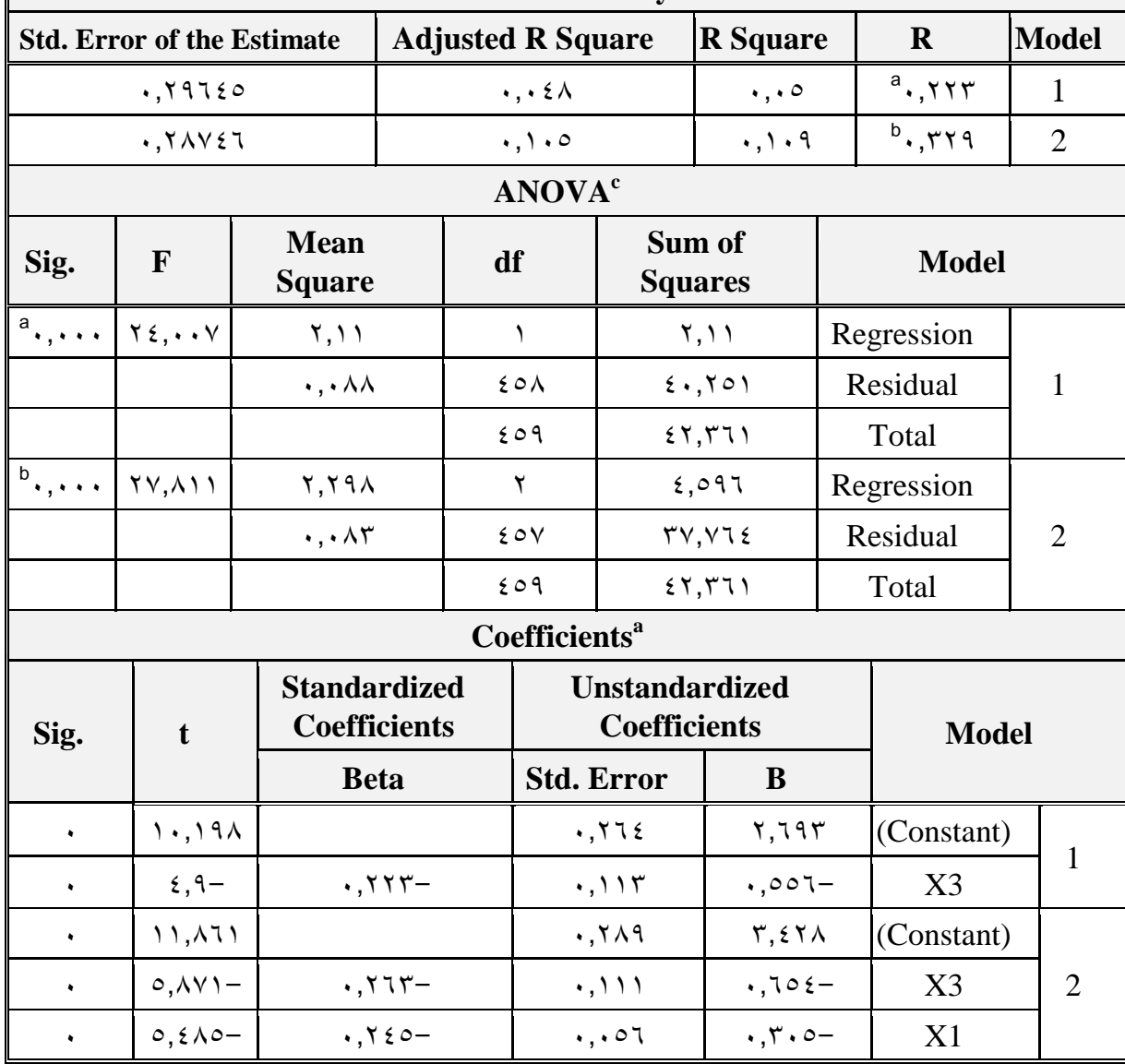

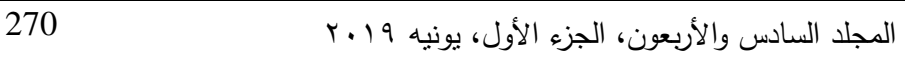


يتضح من الجدول السابق مجموعة من النتائج التي تم التوصل إليها:

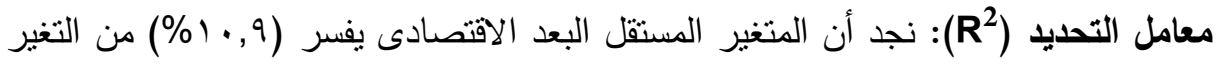

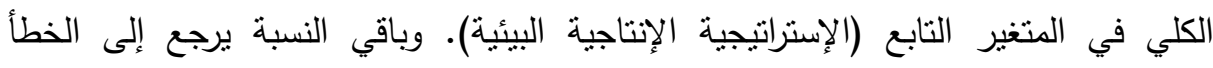

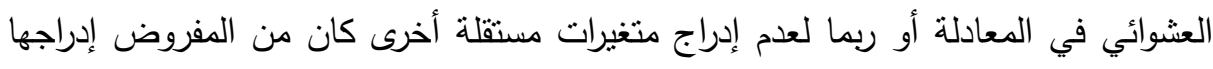
ضمن النموذج. اختبار معنوية المتغير المستقل: باستخدام اختبار (t.test) نجد أن المتغير المستقل البعد

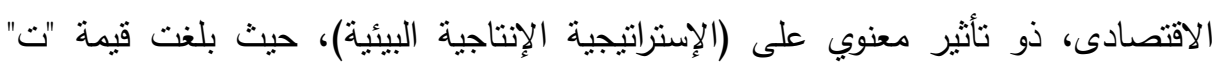

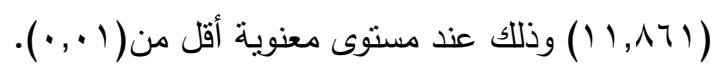

اختبار معنوية جودة توفيق نموذج الانحدار: لاختبار معنوية جودة نوفيق النموذج ككل، نم

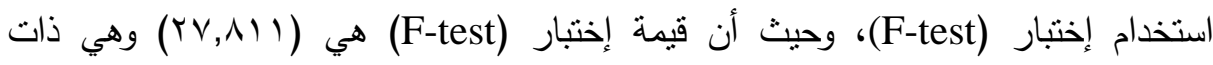

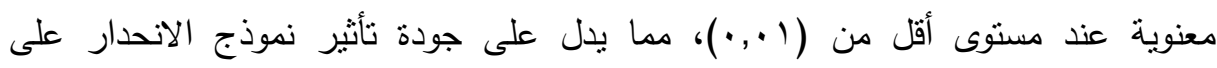
الإستراتيجية الإنتاجية البيئية. وهذا يعنى أنه يمكن تقدير Y3 بقدره تفسيرية 9 , • ( \% كما يلى: $\mathrm{Y} 3=3.428-0.654 \mathrm{X} 3+0.305 \mathrm{X} 1$

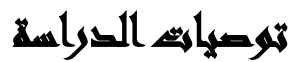

1- يوصى الباحثون بضرورة الاهتمام بتطوير أساليب التحسين الاستراتيجي في مختلف

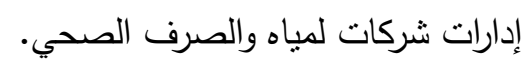
r- الاستفادة من أفكار ووجهات نظر العاملين بالثركات في وضع الخطط التي تساعد على تحسين الاستراتيجية. r- إعادة النظر في روية ورسالة شركات المياه والصرف الصحي بما يواكب النطور في أساليب التخطيط والتحسين الحديثة. ع - ضرورة أن ينم الحفاظ على كل المسؤوليات الإجتماعية تجاه الموظفين وتطويرها وتطبيقها بما يحقق المصلحة بين العاملين والثركات. ๑- يجب على الثركات أن تهنم بأن يكون هناك ألنشكات أنشطة ندريبية لزيادة وعى الموظفين بالمسؤولية الإجنماعية. 


\section{المراليج}

عارف محمود كامل (؟) (Y): إصلاح مقترح لزيادة فعالية الإفصاح عن المسئولية

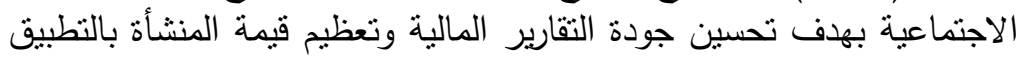
على البيئة المصرية. بوسالة دكتوراه غير منشورة، كلية التجارة، جامعة القاهرة. يونس، عقل، عبد الله: نموذج مقترح لقياس المحتوى المعلوماتي للإفصاح عن المؤشر

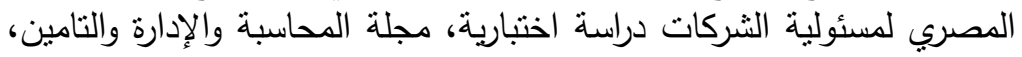

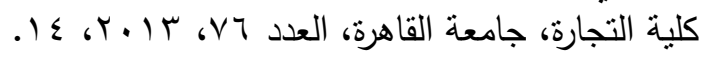

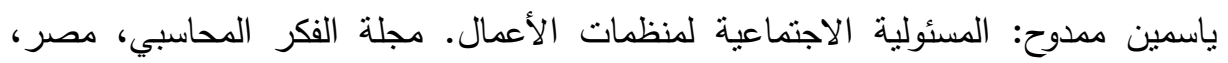

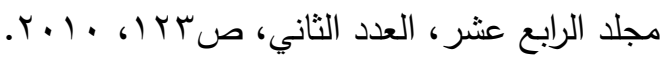

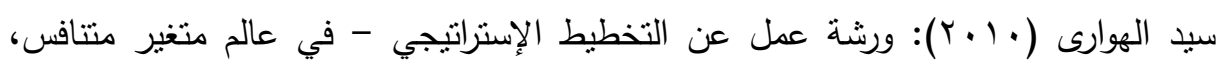

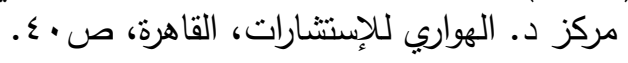

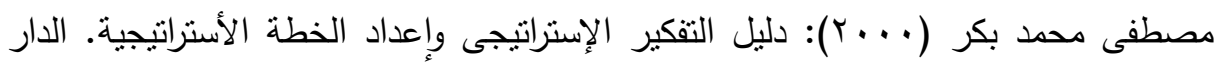

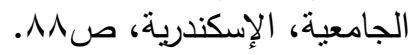

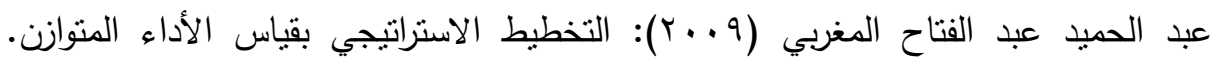

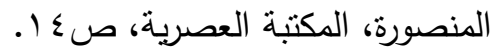

حليمة، زنيزن: تقييم الآليات المطبقة في الإدارة البيئية في المؤسسات الصناعية الجزائرية

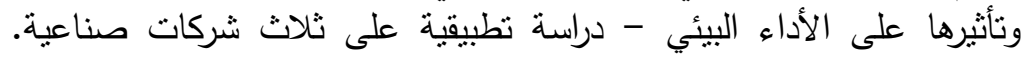

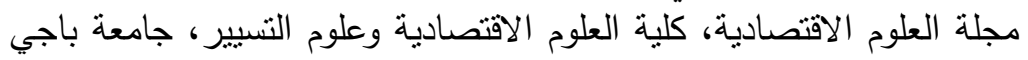

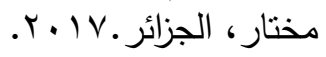

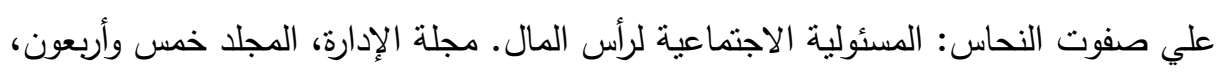

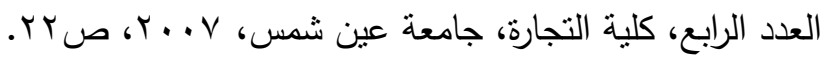

Kenneth, C., A.M.A.: Complete Guide to Strategic Planning for Small Business, Illinois: NTC Publishing Group, 1995 ‘P:VIX.

Luxton, A. (2005): Strategic Planning in Higher Education. General Conference Department of Education, Seventh Day Adventists Silver Spring n VSA. P.22.

Wang, Y. (2011): Corporate Social Responsibility and Stock Performance- Evidence From Taiwan Modem Economy, Nov, pp.788-799.

$$
\text { المجلد السادس والأربعون، الجزء الأول، يونيه } 9 \text {. }
$$


Szymanska, D; Chodkowska, J. (2011): Endogenous resources vitalization of rural areas in shaping sustainable development in Poland. Renewable and sustainable energy reviews, 15 (3), 1497-1501

Samy, M.; Bampton, R. and Halabi, A. (2011): The Relationship Between Corporate Social Responsibility and Profitability The Case of Royal Dutch Shell Pic Corporate Reputation Review, vol. 41, pp. 249.

\title{
IMPROVING MARKETING AND PRODUCTION STRATEGIES OF WATER AND SANITARY DRAINAGE COMPANIES IN EGYPT IN TERMS OF THE SOCIAL RESPONSIBILITY A COMPARATIVE STUDY
}

\author{
Hamdy M. Shata ${ }^{(1)}$; Nader A. Fanous ${ }^{(2)}$ \\ Hisham I. El-Qasas ${ }^{(1)}$; Abdel Qawe A. Mukhtar ${ }^{(3)}$ \\ and Nehal M. Fathy ${ }^{(1)}$
}

1)Post graduate Institute of Environmental Studies \& Research, Ain Shams University 2) Faculty of Commerce, Ain Shams University 3) Faculty of Engineering, Ain Shams University

\begin{abstract}
This study drives at measuring impact of improving strategies of water and sanitary drainage companies in Egypt in term of the social responsibility, to be applied on workers in these companies after identifying the importance and mechanisms of implementing such strategies. In addition, a field study is recruited for identifying the

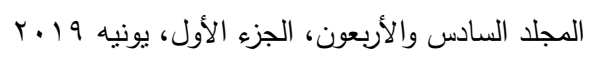


appropriateness range, potentials, and requirements of implementation on the suggestedwater and sanitary drainage companies in Egypt for this study. For achieving the study objectives, a questionnaire form is designed collected through the interview approach, and has included a set of phrases that measures the sample's attitudes towards study variables. The researchers have counted in this study on the mixing between the inductive method and the deductive method through following the theoretical study and the field study.

The researchers have also analyzed data using Kruskal-Wallis Parameter Analysis for analyzing each question in the investigation list and for testing the study hypotheses. The study sample consists of (420) items which is the number of correct forms have be resumed.

The researchers come to several results and recommendations that can be applied to the examined institution (water and sanitary drainage companies in Egypt). The study Recommendations come as follows: The necessity to consider the strategic improvement approaches in the different administrations of the water and sanitary drainage companies. Benefitting from thoughts an points of views of the employees in the companies to set plans that will assist improving the strategy. Reconsidering the water and sanitary drainage companies' message an vision to cope with recent quick advancements in modern approaches and methods of planning and improvement. 